\title{
Research Paper: The Effect of a 6-Week Core Stabil- ity Exercises on the Risk of Falling and Quality of Life in Blind People
}

\author{
Mitra Omidi $^{*}$ (D), Ali Shamsi Majalan¹ (D, Mohammad Karimizadeh Ardakani² ${ }^{\text {(D) }}$, Mohammad Hani Mansoori² (D) \\ 1. Department of Health and Sports Medicine, Faculty of Physical Education and Sports Science, University of Guilan, Guilan, Iran. \\ 2. Department of Health and Sports Medicine, Faculty of Physical Education and Sports Science, University of Tehran, Tehran, Iran.
}

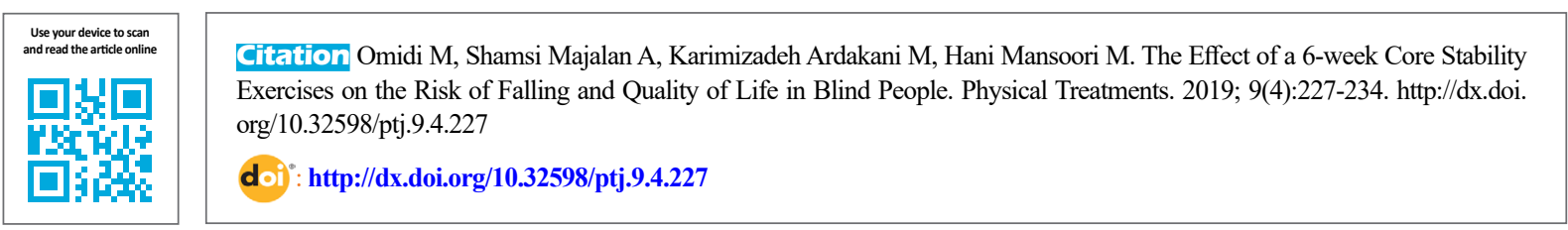

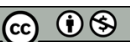

Article info

Received: 21 Jan 2019

Accepted: 07 Jul 2019

Available Online: 01 Oct 2019

Keywords:

Blinds, Visual,

Impairments, Core,

Balance, Quality of life

\section{A B S T R A C T}

Purpose: Visual impairment affects all movement aspects of children. Furthermore, moving, as the primary means of physical education, is essential for promoting health in disabled children. Therefore, the present study determined the effect of core stability exercises on the risk of falling and the quality of life in blind individuals.

Methods: In this quasi-experimental research, 30 blind male and female students were purposively selected and randomly divided into the experimental and control groups. After selecting the students and obtaining their consent to participate in the training program, Functional Reach Test (FRT) and 36-Item Short-Form Health Survey questionnaire (SF-36) were conducted before and after the intervention. The experimental group participated in a 6-week training program for three weekly 45-minute sessions. The obtained data were analyzed by univariate analysis to determine intergroup differences. Moreover, the Paired Samples t-test was applied to determine withingroup differences at a significant level $(\alpha=0.05)$.

Results: The achieved results suggested that after 6 weeks of training, there was a significant improvement in the risk of falling and the quality of life of the experimental group, compared to the pre-training scores of the core stability $(\mathrm{P}<0.05)$; however, there was no significant change in the control group. The Independent Samples t-test revealed a significant difference between the control and experimental groups.

Conclusion: The core stability exercises affected the risk of falling as well as the quality of life in the studied blind individuals. Considering the importance of mobility, especially in children with visual impairments, it is recommended that core stability exercises be used as an effective method to maximize physical mobility in this group.

\section{* Corresponding Author:}

Mitra Omidi, $\mathbf{M S c}$.

Address: Department of Health and Sports Medicine, Faculty of Physical Education and Sports Science, University of Guilan, Iran.

Phone: +98 (936) 2829937

E-mail:mzomidi70@gmail.com 


\section{Highlights}

- Core stability training can improve risk of falling in individuals with visual impairment.

- Core stability training can improve static and dynamic balance in individuals with visual impairment.

- Generally, core stability training improves Quality of life and increases social activities and independence in blind pupulation.

\section{Plain Language Summary}

Less training, along with a lack of visual symptoms, leads to less movement in people with visual impairment. This inactivity causes a delay in motor growth and movement and by the time this changes increases risk of falling in individuals with visual impairment. Blind athletes maintain balance without visual feedback.In simple terms, balance is defined as the ability to hold the body gravity center, which determines the body stability within the support surface area.exercises can increase strength, balance, and speed, and it is beneficial for blinds populations.the exercises in this program can improve their stability and decrease risk of falling.

\section{Introduction}

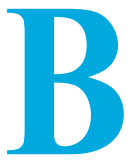

lindness and visual impairments are two of the most critical health and socioeconomic issues in developed and developing countries [1]. Anatomically, the visual system consists of different components with different tasks, which interact with each other in all life stages; thus, it is essential in individuals' autonomy [2]. Various studies have reported that visual impairment affects Quality of Life (QoL) and reduces social activities and independence in individuals [3]. The Quality of Life Index, published annually by the International Journal of Living among 194 countries, suggested that the QoL of the Iranian population reduced from 150 in 2001 to 150 in 2010, compared to other countries. Sarabandi et al. (2014) examined the effect of rehabilitation services on the QoL in blind individuals. This study explored 121 blind and low-vision individuals covered by Zahedan Welfare Organization. The required data were collected using a demographic questionnaire and Quality of Life Index in the blind. The acquired results indicated a significantly higher QoL mean score in individuals receiving rehabilitation services, compared to other. Moreover, these patients obtained significantly higher QoL scores in mobility and self-care domains [4]. Visual impairments affect the sensory development of vision and all aspects of the child's development. It also significantly impact many aspects of early childhood development, such as motor learning (spatial perception, cognitive development, speech and language), as well as social skills [5]. Therefore, it affects the QoL in this group. The sense of vision, plays a direct and essential role in balancing, with the moment-to-moment information it gives to the nervous system from the surrounding environment. Any reduced or impairment in vision leads to alternations in motor function and balance [6]. The lack of vision, in addition to making changes in postural control, results in increased social dependence, restricted daily activities, reduced self-confidence, and increased risk of falls [7].

A study on falls among older people reported that blind elderly are at greater risk of falling, compared to deaf elderly [8]. The risk of falls is affected by various factors, such as a postural change from sitting to standing, muscle weakness, and functional factors like walking speed and balance [9]. Vision significantly affects postural stability maintenance. Vision impairment reduces balance and causes multiple disorders, falls, disability, and recurrent injuries [10]. The risk of falls and loss of balance is higher in people with visual impairments, compared to healthy individuals. With visual impairment, which receives $80 \%$ of our sensory perception in different situations, sensory afferent information is provided through the vestibular or sensory system [11] Blind athletes maintain balance without visual feedback In simple terms, balance is defined as the ability to hold the body gravity center, which determines the body stability within the support surface area. The gravity center is the area where we can calculate the torque of gravity and if the sways increase, it will disturb the balance [12]

Balance is an essential factor for the blind and helps to create spatial integration in them [13]. Exercise can increase strength, balance, flexibility, and speed, and it 
could alter one's biopsychological condition; thus, it is beneficial for everyone, especially in the elderly and disabled populations [14]. Controlling balance depends on the integration of afferent information from the vestibular, visual, and sensory systems. When the activity of one of the systems involved in postural control is reduced or completely lost, decreased performance occurs in other mechanisms involving in postural control [8]. It is therefore essential to provide effective strategies to improve balance and reduce the risk of falling in blinds. The core training has attracted many enthusiasts. The core can be considered as a muscle belt at the motion chain center, i.e., a stabilizing unit for the spine and trunk [15]. Core training increases strength, endurance, and neuromuscular coordination. Internal spinal control, internal abdominal pressure control, and trunk muscle control could also be improved, affecting balance maintenance ability in various dynamic movements [16]. Ahmadi et al. (2012) supported the effect of core training on improving the dynamic balance among individuals with intellectual disabilities [7]. Kahle et al. (2009) also examined the effect of core training on balance in healthy young people. The relevant results indicated a significant improvement in most test directions in the experimental group compared to the controls [17]. Hesari et al. (2011) examined the effect of 8 weeks of core stability training on balance in deaf students. They reported that the experimental group's balance significantly increased in all 4 directions (internal, internal posterior, posterior, \& external posterior) [18].

According to Robinson and Kirby, core stability and strength training are essential in maximizing balance and performance in the movements of the upper and lower extremities. Thus, strength and core stabilization, due to the location of gravity center in this area, reduce the gravity center movement outside of the support surface; it also reduces the sway as well as the risk of falling. The strength of core muscle is among the most impor- tant components of performance improvement. These trainings have beneficial effects on balance; therefore, they reduce the risk of falling. Furthermore, the major problem of blind individuals is motor independence and balance impairment. Thus, the present study investigated the effect of 6 weeks of core stability exercises on the risk of falling and the QoL in the blind.

\section{Materials and Methods}

This was a quasi-experimental study with a pretestposttest and a control group design. It included one intervention group (10 females, 5 males), aged $15 \pm 1.69$ years and a control group (15 females, 5 males), aged $15 \pm 1.64$ years. The current study was conducted on 150 students of Azeri school in Tabriz City, Iran. The study sample consisted of 30 students (20 girls and 10 boys). The inclusion criteria were independent standing and walking abilities and understanding instructions with or without assistance. The exclusion criteria were significant health problems; muscular, neurological or tendon injuries; osteoarticular disease or injuries; the use of medicine influencing balance; the presence of disease or other conditions influencing balance; significant postural problems/limitations, and intellectual limitations. These data were determined by medical records. All subjects' portents' provided written, informed consent to participate in the study and had the right to become aware of their medical records.

The risk of falling was assessed using the Functional Reach Test (FRT). The study participants were requested to reach forward the maximal possible distance while maintaining a fixed base of support with their feet apart in a comfortable stance (approximately shoulder-width apart). The distance was measured (in inches) on a tape measure fixed to a wall. If one reaches less than 6 inches in front, the possibility of falling is high. This test is used to evaluate the balanced posture in patients with stroke,

Table 1. The structure of the six-week training program

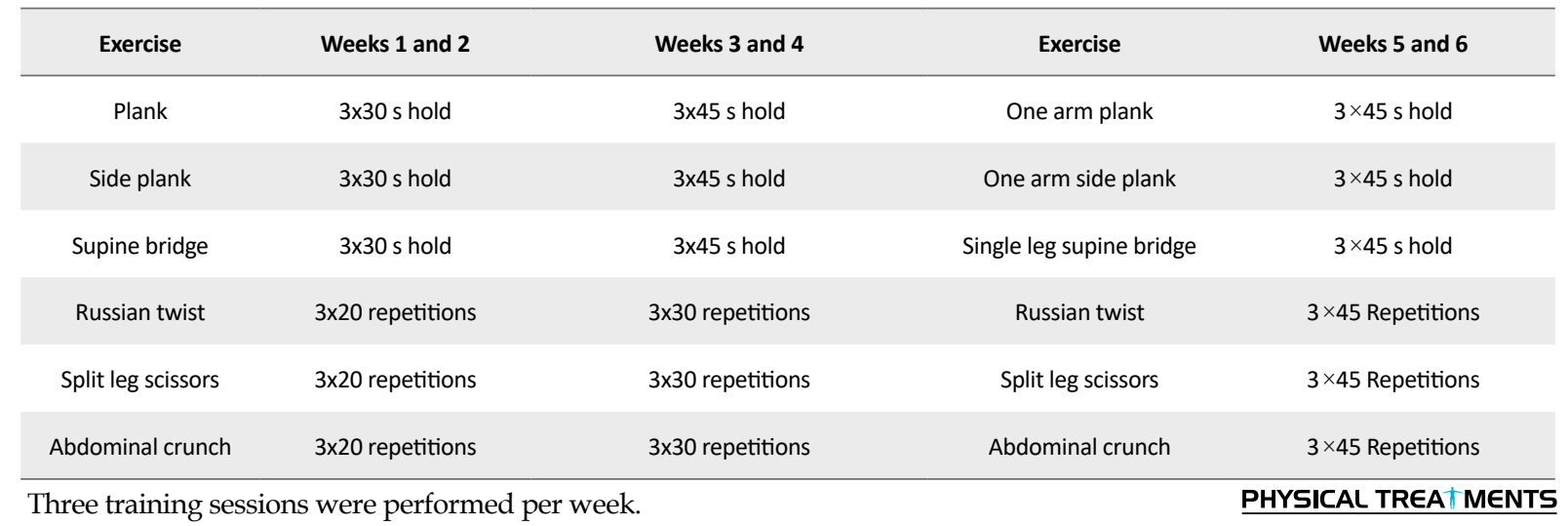


Parkinson's disease, and Multiple Sclerosis (MS) disease [19]. Daubney and Culham [19] reported strong interrater reliability $(\mathrm{r}=0.92)$ and test-retest reliability $(\mathrm{r}=0.98)$ for this test. The QoL was assessed using the 36-Item Short-Form Health Survey questionnaire (SF36]. This scale consists of 36 items and 8 subscales, including physical function, role physical, body pain, general health, vitality, social function, role emotional, and mental health. Each item's score ranges between 0-100; each subscale score is obtained by calculating the mean score of its subscales [20]. The FRT and QoL measurements were conducted for the experimental and control groups before and after performing the core exercises.

During the intervention, both groups continued their regular training sessions for 6 weeks. The experimental group performed core exercise [21] 3 times a week for 6 weeks, while the controls did not. The training program of the experimental group is outlined in Table 1.

Descriptive and inferential statistical methods were used for data analysis. The Shapiro-Wilk test was used to evaluate the data normality. The obtained data were analyzed in SPSS. Paired Samples t-test was used to analyze the pretest-posttest score differences between the groups. The univariate test was used to compare the two groups. The significance level was set at $\mathrm{P}<0.05$.

\section{Results}

According to the Shapiro-Wilk test results, data distribution was normal in both groups. The descriptive data of the study participants are reported in Table 2. Paired Samples t-test was used to determine the pretest-posttest differences in the risk of falling and QoL among the study participants (Table 5) There was a significant improvement in the posttest scores of the risk of falling and QoL in the experimental group $(\mathrm{P}<0.05)$. There was no such significant difference in the control group.

The Univariate analysis results in terms of the differences between the study groups are presented in Table 5 and Table 4. Significant differences were observed between the experimental and control groups in the risk of falling and $\mathrm{QoL}(\mathrm{P}=0.001)$. The posttest values of the experimental group were higher than those of the controls.

The group differences in the risk of falling and the QoL were 0.53 and 0.45 , respectively. In other words, $53 \%$ of the variance of the risk of falling and $45 \%$ of the variance of QoL belonged to the impact of the independent research variable (Table 3 and Table 4).

The Mean \pm SD scores of the experimental group increased by $81.1 \pm 13$; the total Mean \pm SD scores of the SF36 test was $4.3 \pm 51(\mathrm{P}<0.05)$. However, the Mean $\pm \mathrm{SD}$ scores of risk of falling and the total Mean \pm SD scores of SF-36 test remained unchanged after 6 weeks of core stability exercises $(\mathrm{P}=0.17)$. Furthermore, the posttest Mean \pm SD scores of all subscales of QoL, except for the body pain $(\mathrm{P}=0.19)$ and general health $(\mathrm{P}=0.057)$, revealed a significant difference in the experimental group, compared to the Mean \pm SD pretest scores (Table 5).

\section{Discussion}

Research suggests that the major problem of individuals with visual impairments is impaired balance func-

Table 2. Mean $\pm S D$ values of the age, height, and weight of study participants

\begin{tabular}{ccc}
\hline Variables & CG $(\mathbf{n = 1 5})$ & EG $(\mathbf{n = 1 5})$ \\
\hline Age $(\mathrm{y})$ & $15 \pm 1.64$ & $15 \pm 1.69$ \\
Height $(\mathrm{cm})$ & $162 \pm 0.10$ & $161 \pm 0.09$ \\
Weight $(\mathrm{kg})$ & $54.20 \pm 7.89$ & $55.93 \pm 11.41$ \\
\hline
\end{tabular}

Note: $C G=$ control group; $E G=$ experimental group

PHYSICAL TREA MENTS

Table 3. The posttest results of ANCOVA to compare the risk of falling between the study group

\begin{tabular}{ccccccc}
\hline & Sum of Squares & df & Mean Squared & F & P & Eta Squared \\
\hline Group & 20.84 & 1 & 27.84 & 30.84 & 0.001 \\
Error & 24.34 & 27 & 0.90 & - & - \\
Total & 406.13 & 29 & - & - & - \\
\hline
\end{tabular}


Table 4. The posttest results of ANCOVA to compare the QoL between the study groups

\begin{tabular}{ccccccc}
\hline & Sum of Squares & df & Mean Squared & F & Eta Squared \\
\hline Group & 158.33 & 1 & 158.33 & 18.41 & 0.45 \\
Error & 8.59 & 27 & 232.17 & - & - \\
Total & 1069.46 & 29 & - & - & - \\
\hline
\end{tabular}

PHYSICAL TREA $\pitchfork$ MENTS

Table 5. Paired Samples t-test results of dynamic balance and QoL for intergroup comparisons in pretest and posttest phases

\begin{tabular}{|c|c|c|c|c|c|c|}
\hline \multirow{3}{*}{ Variable } & \multicolumn{2}{|c|}{ EG } & \multirow{3}{*}{$\mathbf{P}$} & \multirow{2}{*}{\multicolumn{2}{|c|}{$\begin{array}{c}\text { CG } \\
\text { Mean } \pm S D\end{array}$}} & \multirow{3}{*}{$\mathbf{P}$} \\
\hline & \multicolumn{2}{|c|}{ Mean $\pm S D$} & & & & \\
\hline & Pre-test & Post-test & & Pre-test & Post-test & \\
\hline FRT & $10.73 \pm 3.57$ & $12.54 \pm 3.43$ & $0.0001^{*}$ & $9.79 \pm 3.58$ & $9.71 \pm 3.58$ & 0.362 \\
\hline Physical functioning & $87.46 \pm 17.33$ & $91.73 \pm 15.91$ & $0.001^{*}$ & $95.53 \pm 6.66$ & $90.93 \pm 9.59$ & 0.08 \\
\hline Role limitations (physical) & $75.66 \pm 17.95$ & $86.53 \pm 16.67$ & $0.009^{*}$ & $87.73 \pm 8.68$ & $80.46 \pm 14.08$ & 0.06 \\
\hline Bodily pain & $30.66 \pm 14.77$ & $34.40 \pm 14.36$ & 0.192 & $46.53 \pm 23.36$ & $48.26 \pm 22.59$ & 0.461 \\
\hline General health perceptions & $56.40 \pm 8.18$ & $60.00 \pm 5.85$ & 0.057 & $63.20 \pm 5.89$ & $65.20 \pm 7.16$ & 0.224 \\
\hline Energy/vitality & $54.53 \pm 3.33$ & $58.13 \pm 8.00$ & $0.045^{*}$ & $61.66 \pm 9.62$ & $60.13 \pm 9.50$ & 0.5 \\
\hline Social functioning & $57.26 \pm 11.18$ & $62.00 \pm 10.82$ & $0.013^{*}$ & $61.33 \pm 10.60$ & $62.00 \pm 12.07$ & 0.751 \\
\hline Role limitations (emotional) & $69.93 \pm 15.65$ & $80.93 \pm 18.47$ & $* 0.007$ & $75.33 \pm 14.78$ & $87.66 \pm 16.86$ & 0.083 \\
\hline Mental health & $52.33 \pm 12.02$ & $56.13 \pm 2.49$ & $0.002^{*}$ & $52.86 \pm 11.17$ & $53.86 \pm 13.94$ & 0.570 \\
\hline Total & $62.20 \pm 5.05$ & $65.60 \pm 5.56$ & $0.0001^{*}$ & $68.60 \pm 7.08$ & $67.33 \pm 6.61$ & 0.170 \\
\hline
\end{tabular}

CG: control group; EG: experimental group

PHYSICAL TREA $\ M E N T S$

*P $\leq 0.05$

tions, which increases their risk of falling; as a result, it reduces motor independence and affects their QoL. An essential treatment objective of therapeutic interventions for children with visual impairments is to enhance their capacity to perform different functional skills. The present study investigated the effect of core stability exercises on the risk of falling and QoL among blind individuals. The obtained results indicated that core stability exercises improved the risk of falling and QoL in individuals with visual impairments. In addition to improving the overall score of QoL, the achieved results suggested a significant difference in all subscales of QoL, except for physical pain and general health. However, the control group demonstrated no significant difference in any of the variables of risk of falling and $\mathrm{QoL}(\mathrm{P}>0.05)$. The study results also suggested that the highest obtained score in the mental health subscale was equal to 0.67 , and the lowest score in the pain subscale was 0.01 . In other words, $67 \%$ of the variance of mental health vari- able and $1 \%$ of the variance of pain in body variables were related to the effect of the independent variable.

The significant differences between both groups after 6 weeks of exercising might credit to the core stability effect for activating the optimal posture of the lumbar and pelvic regions. Core stability exercises reinforce the muscles around the trunk and pelvic regions that help to stabilize the body and head during limb movements; this is achieved by tonic or postural muscles during the entire body exercises [22].

The results of research on the blind reported that closed-eye exercise stimulates other senses by blocking visual information; thus, it improves balance ability. Mavrovouniotis et al. (2013) examined the effect of Greek dance and Pilates combined exercises on blind children. Their results revealed a significant difference in the static and dynamic balance in the experimental group [23]. In a study by Bonan et al., closed-eye exercise was per- 
formed by 20 chronic stroke patients. The relevant results indicated that the balance ability was significantly improved [24]; this finding is attributed to the forced use of vestibular information and proprioception, as a result of decreased visual information. Their result is consistent with the present study. Salari et al. [25] also studied the effect of core stability exercises on the balance of blind female athletes. They divided 30 blind female athletes into the control and experimental groups.

Moreover, they used the one-leg standing test to evaluate the static balance and Y Balance Test to evaluate dynamic balance. The collected results revealed a significant increase in static and dynamic balance in the anterior and posterior internal and posterior external directions and overall balance in the experimental group compared to the controls. Furthermore, improvements in the dynamic balance and gait performance after core stability training could be attributed to the activation of the core muscles, which also reduces the risk of falling. Sadeghi et al. [26] conducted an 8-week core stability training for 3 days a week on 28 participates. They observed a significantly improved walking speed and dynamic balance in the experimental group compared with the controls. In the blind, due to the lack of visual information, the general motor information and motor patterns in the central nervous system are reduced; this affects the balance function of the individual and leads to poor performance in the blind, compared to their healthy peers [27]. Exercise movements improve and integrate the musculoskeletal system in postural control. In addition, the body central area is of particular importance; it is the anatomical location in the body where the gravity center is located and the movements originate from it. It responds to disturbances in dynamic stability and transfer forces from the trunk. As a result, strengthening the core muscles seems to improve the neuromuscular system and reduce body sway and gravity center displacement [16]. Furthermore, abdominal and back exercises concentrated on the muscle force and stimulated the neuroadaptative frameworks; in turn, that prompted the early advancement in the stability and proprioceptors activity [28]. Mohammadi [29] examined the effects of 8 weeks of core stability training on the motor fitness among 26 elite athletes in worldwide.

The Medicine Ball Throwing, ball throwing, single leg jump, static lacquer balance, and dynamic Y balance and stroke tests were used for data collection. They reported a significant difference between all variables in the experimental group compared to the controls. The results of the present and previous research studies indicated that core training could be beneficial in improving bal- ance by strengthening the muscles often associated with spine and pelvic control. To justify this result, we can highlight the effect of Swiss ball training.

The effect of Swiss ball exercises on dynamic balance can point to improving postural control on the ball and lifting of body weight from muscles and joints, as well as performing a wide range of motions without the odds of injury. The disruptive forces created by being placed on the ball can provide the appropriate activity to challenge the systems involved with balance. The combination of movement, movement speed, and frequency can also improve flexibility and reaction; these are important in maintaining balance [30].

Additionally, according to the present study, the balance function and QoL of the experimental group were better than those of the controls. This can be justified by the principle that core stability exercises facilitate neuromuscular recall. Furthermore, these exercises are more likely to facilitate neuromuscular and more effective exercise in subjects with poor postural control

The present study had some limitations. First, it lacked a long-term follow-up of the children to determine whether the improvement observed in the short term was maintained over time. Second, the small sample size might limit the generalization of the obtained data. Therefore, further studies that include a larger number of children with visual impairments and longer training time are recommended for an optimal generalization of the results. Furthermore, future studies investigating the effect of core stability exercises within the context of occupational therapy for children with visual impairments may be useful to direct the clinical practice.

\section{Conclusion}

The core stability program is recommended to be included in the training programs for enhancing the balance and QoL in children with visual impairments.

\section{Ethical Considerations}

\section{Compliance with ethical guidelines}

All ethical principle were considered in this artical, and this study was confirmed by the Ethics Committee of the ministry of Health (Code: IR.SSRC.REC.1398.O48). 


\section{Funding}

This manuscript was drafted from an MSc. thesis conducted at the faculty op Physical Education and Sport at Guilan University.

\section{Authors' contributions}

Original idea, protocol development, abstract, and data analysis: Mitra Omidi, Ali Shamsi Majalan, Mohammad Karimizadeh Ardakan; Manuscript preparation: all authors.

\section{Conflict of interest}

The authors declared no conflict of interest.

\section{Acknowledgments}

The authors would like to express their sincere gratitude to the children and their parents who participated in this study.

\section{References}

[1] Ramezani A, Pardis M, Rafati N, Kazemi-Moghaddam M, Katibeh M, Rostami P, et al. Causes of visual impairment among patients referred to a visual rehabilitation clinic in Iran. Korean Journal of Ophthalmology. 2012; 26(2):80-3. [DOI:10.3341/kjo.2012.26.2.80] [PMID] [PMCID]

[2] Mohammadi F. [Assessment of CNS function on postural control with and without Somatosensory and Vestibular perturbation in goalball players in comparison with nonathlete blind and sighted subjects (Persian)] [MSc. Thesis]. Tehran: University of Tehran; 2008.

[3] West SK, Munoz B, Rubin GS, Schein OD, Bandeen-Roche K, Zeger S, et al. Function and visual impairment in a population-based study of older adults: The SEE project; Salisbury Eye Evaluation. Investigative Ophthalmology \& Visual Science. 1997; 38(1):72-82. [PMID]

[4] Sarabandi A, Mobaraki H, Kamali M, Chabok A, Soltani S. [The effect of rehabilitation services on Quality of Life for the blind (Persian)]. Modern Rehabilitation. 2014; 7(4):48-56.

[5] Ahmadi Barati A, Ahmadi Barati S, Ghaeini S, Behpour N, Letafatkar A. Comparing the effect of mental, physical and mental-physical exercises on the balance capability of blind students. Journal of Rehabilitation Sciences \& Research. 2013; 9(3):415-23.

[6] Juodžbalienè V, Muckus K. The influence of the degree of visual impairment on psychomotor reaction and equilibrium maintenance of adolescents. Medicina. 2006; 42(1):49-56. [PMID]

[7] Aali S. [Study of the structural profile and physical fitness in children with sensory impairment (Persian) [MSc. Thesis]. Rasht: University of Guilan; 2012
[8] Soares AV, Oliveira CSRd, Knabben RJ, Domenech SC, Junior B, Gomes N. Postural control in blind subjects. Einstein (Sao Paulo). 2011; 9(4):470-6. [DOI:10.1590/s167945082011ao2046] [PMID]

[9] Cheng PT, Liaw MY, Wong MK, Tang FT, Lee MY, Lin PS, The sit-to-stand movement in stroke patients and its correlation with falling. Archives of Physical Medicine and Rehabilitation. 1998; 79(9):1043-6. [DOI:10.1016/S00039993(98)90168-X]

[10] Blomqvist S, Rehn B. Validity and reliability of the Dynamic One Leg Stance (DOLS) in people with vision loss. Advances in Physiotherapy. 2007; 9(3):129-35. [DOI:10.1080/14038190701395671]

[11] Lord SR, Menz HB. Visual contributions to postural stability in older adults. Gerontology. 2000; 46(6):306-10 [DOI:10.1159/000022182] [PMID]

[12] Chek P. Swiss ball exercises for swimming, soccer and basketball. Sports Coach. 1999; 21:12-3.

[13] Çolak T, Bamaç B, Aydin M, Meriç B, Özbek A. Physical fitness levels of blind and visually impaired goalball team players. Iso kinetics and exercise science. 2004; 12(4):247-52. [DOI:10.3233/IES-2004-0182]

[14] Tsang WW, Wong VS, Fu SN, Hui-Chan CW. Tai Chi improves standing balance control under reduced or conflicting sensory conditions. Archives of Physical Medicine and Rehabilitation. 2004; 85(1):129-37. [DOI:10.1016/j. apmr.2003.02.002] [PMID]

[15] Tse MA. Exploring the impact of core stability on performance [PhD. Thesis]. Pokfulam: University of Hong Kong; 2009.

[16] McCaskey A. The effects of core stability training on star excursion balance test and global core muscular endurance [MSc. Thesis]. Toledo, Ohio: University of Toledo; 2011.

[17] Kahle NL. The effects of core stability training on balance testing in young, healthy adults [BSc. Thesis]. Toledo, Ohio: University of Toledo; 2009. [DOI:10.3928/1942586420090301-03]

[18] Hessari FF, Norasteh AA, Daneshmandi H, Ortakand S. The effect of 8 weeks core stabilization training program on balance in deaf students. Medicina Sportiva. 2011; 15(2):5661. [DOI:10.2478/v10036-011-0010-4]

[19] Duncan PW, Weiner DK, Chandler J, Studenski S. Functional reach: A new clinical measure of balance. Journal of Gerontology. 1990; 45(6):M192-M7. [DOI:10.1093/ geronj/45.6.M192] [PMID]

[20] Khajavi D, Farrokhi A, Jaberi-Moghaddam AA, Kazemnejad A. Effect of strength and balance training program on maintaining balance and quality of life in older male adults with fear of fall. Iranian Journal of Ageing. 2016; 11(2):270-9. [DOI:10.21859/sija-1102270]

[21] Araujo S, Cohen D, Hayes L. Six weeks of core stability training improves landing kinetics among female capoeira athletes: A pilot study. Journal of Human Kinetics. 2015; 45(1):27-37. [DOI:10.1515/hukin-2015-0004] [PMID] [PMCID]

[22] Marshall PW, Murphy BA. Core stability exercises on and off a Swiss ball. Archives of Physical Medicine and Rehabili- 
tation. 2005; 86(2):242-9. [DOI:10.1016/j.apmr.2004.05.004] [PMID]

[23] Mavrovouniotis FI, Papaioannou CS, Argiriadou EA, Mountakis CM, Konstantinakos PD, Pikoula IT, et al. The effect of a combined training program with Greek dances and Pilates on the balance of blind children. Journal of Physical Education and Sport. 2013; 13(1):91-100. [DOI:10.7752/ jpes.2013.01016]

[24] Bonan IV, Colle FM, Guichard JP, Vicaut E, Eisenfisz M, Huy PTB, et al. Reliance on visual information after stroke. Part I: Balance on dynamic posturography. Archives of Physical Medicine and Rehabilitation. 2004; 85(2):268-73. [DOI:10.1016/j.apmr.2003.06.017] [PMID]

[25] Salari A, Sahebozamani M, Daneshmandi H. [The effect of core stability training program on balance in blind female athletes (Persian)]. Journal of Health and Development. 2013; 20(6):585-95.

[26] Sadeghi S, Mahdavinezhad R, Kamali A. [Determine the effect of core stability exercises on the balance and speed of walking blind students (Persian)]. Research on Sports Rehabilitation. 2016; 4(7):21-30. [DOI:10.22084/RSR.2016.1590]

[27] Ray CT, Horvat M, Croce R, Mason RC, Wolf SL. The impact of vision loss on postural stability and balance strategies in individuals with profound vision loss. Gait \& Posture. 2008; 28(1):58-61. [DOI:10.1016/j.gaitpost.2007.09.010] [PMID]

[28] Akuthota V, Nadler SF. Core strengthening. Archives of Physical Medicine and Rehabilitation. 2004; 85 (3 Suppl 1):S86-92. [DOI:10.1053/j.apmr.2003.12.005] [PMID]

[29] Moghaddam M MZA, Mohammadi F, . The Effect of core Stability Exercise on Motor Fitness of Elite Athletes in Golbal. Journal of Sports Medicine Studies,. 2018, 10 (23),. [In Persian].

[30] da Silva ES, Fischer G, da Rosa RG, Schons P, Teixeira LBT, Hoogkamer W, et al. Gait and functionality of individuals with visual impairment who participate in sports. Gait \& Posture. 2018; 62:355-8. [DOI:10.1016/j.gaitpost.2018.03.049] [PMID] 